\title{
Evaluation of Eustachian Tube Function on Chronic Suppurative Otitis Media
}

\author{
Rosydiah Rahmawati ${ }^{1}$, Haris Mayagung Ekorini ${ }^{1}$ \\ ${ }^{1}$ Medical Staff, Department of Otorhinolaryngology Head and Neck Surgery, Faculty of Medicine, Universitas \\ Airlangga-Dr. Soetomo General Academic Hospital, Surabaya, Indonesia
}

\begin{abstract}
Introduction: Many literatures reported that poor aeration in the middle ear due to Eustachian tube dysfunction is an important factor that plays a role in causing acute and chronic otitis media.

Objective: To assess Eustachian tube function (ETF) and to confirm Eustachian tube condition during surgery on chronic suppurative otitis media (CSOM) patients.

Method: This study employed a prospective design, in which participants were examined for ETF before and after surgery. The examination used Toynbee's procedure with impedance audiometry. The examination results were analysed using Pearson's product-moment test with $\mathrm{p}<0.05$.

Results: The average patient's age was $36.27 \pm 5.98$ years, with an age range of 12 to 67 years. Most participants had no cholesteatoma (59.89\%), perforation (50.00\%), and experienced conductive hearing loss $(54.54 \%)$. There was no significant difference between ETF and Eustachian tube during surgery $(p=0.439)$.

Conclusion: This study reported that most CSOM patient had total impaired ETF with open Eustachian tube.
\end{abstract}

Keyword: Eustachian tube function, CSOM, Toynbee's test.

\section{Introduction}

Pathogenesis of chronic suppurative otitis media (CSOM) is multifactorial with various overlapping factor. The risk of developing CSOM involves a complex interplay between host immunity and microbial pathogenicity, which in turn is affected by host and microbe genetics, as well as by environmental factors (particularly those that affect risk of exposure

\section{Corresponding Author: \\ Rosydiah Rahmawati}

Department of Otorhinolaryngology Head and Neck Surgery, Faculty of Medicine, Universitas Airlangga

- Dr. Soetomo General Academic Hospital, Jalan

Mayjend Prof. Dr. Moestopo No. 6-8, Airlangga,

Gubeng, Surabaya, East Java 60286, Indonesia

e-mail: rosydiahrahmawati60@gmail.com

Phone: $+6231-5501649$ to bacteria) and by therapeutic interventions. Previous literatures reported that poor aeration of middle ear due to ventilatory dysfunction of Eustachian tube is a key factor in acute and chronic otitis media ${ }^{(1-3)}$.

A normally functioning Eustachian tube is an essential physiological requirement for a healthy middle ear and normal hearing. The three physiological functions of Eustachian tube are pressure regulation (ventilation), protection and clearance (drainage). Pressure regulation can be impaired by failure of the opening mechanism (functional obstruction) and anatomical (mechanical) obstruction. Moreover, anatomical modelling suggests that Eustachian tube narrowing is unlikely to significantly impede gas exchange ${ }^{(3,4)}$.

This study aimed to assess Eustachian tube function (ETF) in patient with CSOM using impedance audiometry (Toynbee's test) before surgery. This study evaluated the Eustachian tube condition during surgery, whether there was obstruction from pathologic tissue 
or not to confirm the ETF result on CSOM patients. Therefore, this study can prove whether tubal disorders is a major risk of CSOM.

\section{Materials and Method}

Participants: Participants in this study were chronic suppurative otitis media patients. The inclusion criteria were patients diagnosed with chronic suppurative otitis media $(5,6)$, patients indicated for surgery, and received therapy for $>2$ weeks after surgery. Participant exclusion criteria included tympanometry type $\mathrm{B}$, unreadable ETF, and uncooperative patients. Participants received an explanation regarding their rights and obligations during the research. Participants first filled out informed consent.

Design: This study used a prospective clinical design conducted for 6 months (January to July 2018). There were 22 participants in this study. The researchers conducted an ethics test at the ethics committee of Dr. Soetomo General Academic Hospital, Surabaya, Indonesia, prior to the study. Detailed history was taken and clinical examination and pure tone audiometry was performed. Audiometry pure tone examination used Interacoustics AD226 Clinical Audiometer (Interacoustics A/S, Assens, Denmark) based on standard operational procedures ${ }^{(7)}$. Eustachian tube function was assessed using Toynbee's test with impedance audiometry using Madsen Otoflex 100 (GN Otombtrics A/S, Taastrup, Denmark). Cases were categorised in normal ETF, partial impaired and total impaired ETF, depending upon tests results ${ }^{(8)}$.

Toynbee's Measurement: The impedance audiometer is programmed to artificially increase or decrease the air pressure in the middle ear and then record the change of air pressure in the middle ear each time when the patient swallows. The patient was asked to swallow repeatedly and recorded graphically by impedance audiometer. Change of pressure during swallowing was recorded as step ladder type of graph, that is, normal. If some residual pressure persists even after five swallows, the tubal function is considered to be partially impaired. If positive or negative pressure built up by the impedance audiometer cannot be neutralised at all by repeated swallowing, then the ETF is considered to be totally impaired ${ }^{(9)}$.

All study subjects underwent surgery as therapy. During surgery, otologist evaluated the condition of eustachian tube and pathological tissues that affect tubal dysfunction. The condition of eustachian tube is divided into open and closed. Surgery procedures were adjusted to participant diagnosis according to CSOM management guidelines ${ }^{(2,5,10-12)}$.

Statistical Analysis: The results of the study were presented in the form of mean \pm standard deviation (SD) or median (minimum - maximum) and percentage (\%). The results were also displayed in the form of tables. Statistical analysis used paired t test or wilcoxon test. Static analysis used IBM SPSS Statistics software version 23.0 (IBM Corp., Armonk, NY, USA). Statistical test results were significant if $\mathrm{p}<0.05$.

\section{Results}

Characteristics of Patients: This study examined 22 participants between age group of 12 to 67 years with CSOM. Male to female ratio was $1: 1$. The average patient's age was $36.27 \pm 5.98$ years, with a median value of 42.27 years Otorrhoea was the main complaint in all cases. Most participants were Javanese (17 participants; 77.27\%) and the rest were Madurese. This study found 9 participants (40.91\%) with cholesteatoma and 13 participants $(59.89 \%)$ without cholesteatoma. On otoscope, 11 participants $(50.00 \%)$ had subtotal perforation, 5 participants $(22.73 \%)$ had central perforation, 5 participants $(22.73 \%)$ had attic perforation, and 1 participant (4.54\%) with marginal perforation. Pure tone audiometry test showed that 12 participants $(54.54 \%)$ had conductive hearing loss, 5 participants $(22.73 \%)$ had mixed hearing loss and 5 participants $(22.73 \%)$ had sensorineural hearing loss (Table 1). The severity of participant's hearing loss was mostly in the moderate category by 14 participants (63.64\%), while the rest was in the mild category ( 8 participants; $36.36 \%$ ).

Eustachian Tube Function: The results of impedance audiometry showed that 7 participants (31.82\%) had normal eustachian tube function, 3 participants (13.64\%) had partially impaired ETF and 12 participants (54.54\%) had totally impaired ETF. During surgery, there were 4 patients $(19 \%)$ with blocked eustachian tube and 18 patients $(81 \%)$ with open ET. There were no significant differences between ETF and Eustachian tubes during surgery in participants ( $p=$ 0.439; Table 2).

\section{Discussion}

CSOM affects 65 - 330 million people worldwide, mainly in developing countries. CSOM usually develops 
in the first years of life but can persist during adulthood. Studies investigating the relationship between age and otitis media reported that otitis media has its peak incidence and prevalence in preschool years $(1,2)$. The maximum number of participants in this study $(9$ participants; $40.91 \%$ ) were in the age group of $21-30$ years, while the minimum number of participants $(2$ participants; 9.09\%) were in the age group of 31-40. The age group of 21-30 year as second decade of life is the most active time of one's life as more people seek medical advice for discharging ear ${ }^{(13)}$. This study examined 5 participants $(22.73 \%$ ) with age over 40 , due to patient social economy status and patient knowledge about operation procedure.

Both sexes were equally affected, with $50.00 \%$ participants were male and $50.00 \%$ participants were female in this study. However, several studies reported that otitis media was more common among males than females. However, when a female patient is in a marriage age (18-20 years), awareness suddenly arouses in the patient and parents to prevent the discredit of discharging ear and hence females pay more attention to discharging ear than the male $\mathrm{e}^{(2,13)}$.

Subtotal perforation was found in 11 participants $(50.00 \%)$. Subtotal perforation occurred in pars tensa, a form of central perforation that leaves only the edge of tympanic membrane and safe type of chronic otitis media. Other perforation was central (23\%), attic (23\%) and marginal (14\%). Marginal and attic perforation were dangerous type because it directly contacts to annulus, sulcus tympanicus and mastoid cavity ${ }^{(1,2)}$.

Audiometry result showed conductive hearing loss in 12 participants $(54.54 \%)$. It was caused by tympanic membrane perforation dan ossicular chain destruction. Mixed and sensoryneural hearing loss were each found in 5 participants $(22.73 \%)$. Cochlea function may be affected by bacterial toxins percolating through the round window and by direct invasion of pathogenic organism that result in inflammatory response $\mathrm{e}^{(1,2)}$.

Eustachian tube serves the function of ventilation, pressure balance and clearance of secretions in middle ear. Physiologically, the neutralisation of negative middle ear pressure is brought about by intermittently opening the Eustachian tube and allowing air to pass through it such that the air pressure within the middle ear cavity is brought back more or less to the same level as that of the atmospheric air pressure. The intermittent opening of the Eustachian tube is caused by contraction of tensor palatini and partially the levetor veli palatini muscles. These muscles contract during swallowing. Therefore, for assessment of Eustachian tube function, it has to be essentially ascertained whether an artificially increased or decreased middle ear pressure can be neutralised and brought back to ambient pressure by swallowing ${ }^{(3,13)}$.

Tests indicating patency of the Eustachian tube were Valsalva test, Pneumatic otoscopy/Siegalisation, Ear drops test, Nasopharyngoscopy, Tympanometry with Toynbee test. In this study, Eustachian tube function was examined with impedance audiometry with Toynbee test. Toynbee test is the only test which gives idea of Eustachian tube function that is opening and closing mechanism for equalisation of pressure in middle ear. Among all the above-mentioned tests, there are some cons, but only Toynbee's test gives accurate and reliable results. Hence, Toynbee's test is considered an ideal test to assess Eustachian tube function ${ }^{(3,14,15)}$.

Normal ETF was found in $31.81 \%$ participants and impaired in $68.18 \%$ participants, with total impaired in 12 participants $(54.54 \%)$ and partial impaired in 3 participants $(13.64 \%)$. This result was similar to a study conducted by Tadke et al. in 2017, showing that in 60 cases of Eustachian tube patency test, there were 39 participants $(65 \%)$ had normal ETF and 21 (35\%) had impaired function. There were differences in the subject studied, as Tadke examined patients with central tympanic perforation and dry ear ${ }^{(13)}$.

Study carried out by different authors showed a variation in the percentage of Eustachian tube function. Normal ETF was observed as $51 \%$ by Holmquist showed $16 \%$, Sharp $7.5 \%$ and Dutta 26\%. This difference may be caused by different method used to evaluate the Eustachian tube function and at different time of disease $\operatorname{activity}^{(13)}$.

Shreyas et al. in 2012 mentioned that a modern impedance audiometer offers facility to ascertain the physiological function of Eustachian tube, not only in the intact tympanic membrane but also in the presence of perforation. This audiometer is quick, non-invasive, does not require participant's compliance, accurate and affordable and it offers the best means of assessing the Eustachian tube function. The results of the tympanometric assessment in their study were $80 \%{ }^{(16)}$.

As per study conducted by Priya et al. in 2012, the Eustachian tube function is related to duration, type and 
location of tympanic membrane perforation in chronic suppurative otitis media. Impedance audiometry is a simple, non-invasive method to evaluate the Eustachian tube function ${ }^{(15)}$. As per studies conducted by Gimenez et al. in 1993, Xiao et al. in 2006 and Nishant Kumar et al. in 2012, Eustachian tube function is related to duration, type and location of tympanic perforation in chronic suppurative otitis media ${ }^{(14)}$.

Common dysfunction of ET is obstruction as a result of local mucosal changes by otitis media, especially in chronic condition. Obstruction may occur due to pathologic tissue as granulation or cholesteatoma that extend toward Eustachian tube. Toxin or infection product from microbe can cause tubal dysfunction ${ }^{(16)}$.

Condition of Eustachian tube during surgery were quite different from ETF result, as 18 participants (81.82\%) had open ET and 4 participants (18.18\%) had closed ET. During surgery, evaluation of ET was only conducted on the distal or osseous portion, therefore the researchers could not know the function of proximal or cartilagenus portion. Eustachian tube function (ETF) has been the central focus as a prognostic factor because of its presumed primary role in the pathogenesis of otitis media and in clearance of the middle ear cavity. The success of tympanoplasty depends on many factors, one of which is adequate Eustachian tube function. It is believed that tubal dysfunction is one of the most important factors for failure of tympanoplasty. Though there are many factors that influence graft uptake rate, a good preoperative tubal function is one of the prerequisite for high rate of success rates in terms of graft uptake following tympanoplasty ${ }^{(13,14)}$.

Table 1. Characteristics of Participants

\begin{tabular}{|l|c|}
\hline Characteristics & Mean \pm SD or n (\%) \\
\hline Age & $\mathbf{3 6 . 2 7} \pm \mathbf{5 . 9 8}$ \\
\hline Race & $17(77.27)$ \\
Javanese & $5(22.73)$ \\
Madurese & \\
\hline Sex & $11(50.00)$ \\
Male & $11(50.00)$ \\
Female & $11(50.00)$ \\
\hline Perforation & $5(22.73)$ \\
Central & $5(22.73)$ \\
Attic & $1(4.54)$ \\
Marginal & \\
\hline Hearing Loss & $12(54.54)$ \\
Conductive & $5(22.73)$ \\
Mixed & $5(22.73)$ \\
Sensorineural & \\
\hline
\end{tabular}

$\mathrm{SD}=$ Standard deviation

Table 2. Eustachian tube function and condition on surgery

\begin{tabular}{|l|c|c|}
\hline \multirow{2}{*}{ EFT } & \multicolumn{2}{|c|}{ Condition Eustachian Tube } \\
\cline { 2 - 3 } & Open & $1(4.54)$ \\
\hline Normal & $6(27.27)$ & $0(0.00)$ \\
\hline Partial impairment & $3(13.64)$ & $3(13.64)$ \\
\hline Total impairment & $9(40.91)$ & \\
\hline
\end{tabular}

Statistical test results indicate $\mathrm{p}=0.439$

\section{Conclusions}

Eustachian tube function can be evaluated on CSOM patients by Toynbee's test with impedance audiometer. Its advantages include quick, non-invasive, does not require patients' compliance, accurate and affordable and it offers the best means of assessing the Eustachian tube function. This study showed that most CSOM patients $(54.54 \%)$ had total impaired ETF. There were 3 (13.64\%) CSOM patients with partial impaired ETF and 7 (31.82\%) CSOM patients with normal ETF. This result showed that CSOM can cause Eustachian tube dysfunction.

Conflict of Interest: The authors report no conflict of interest in this publication.

\section{Funding: None}

Ethics Statement: All procedures performed in studies involving human participants were in accordance with the ethical standards of the Ethics Committee in Dr. Soetomo General Academic Hospital, Surabaya, Indonesia. 


\section{References}

1. Bhutta MF, Thornton RB, Kirkham L-AS, Kerschner JE, Cheeseman MT. Understanding the aetiology and resolution of chronic otitis media from animal and human studies. Disease Models \& amp; Mechanisms. 2017;10(11):1289-300.

2. Mittal R, Lisi CV, Gerring R, Mittal J, Mathee $\mathrm{K}$, Narasimhan G, et al. Current concepts in the pathogenesis and treatment of chronic suppurative otitis media. J Med Microbiol. 2015;64(10):110316.

3. Bluestone CD. Anatomy and physiology of the eustachian tube system. Head and Neck SurgeryOtolaryngology Philadelphia: Lippincott Williams \& Wilkins. 2006:1253-64.

4. Kumar N, Chilke D, Puttewar MP. Clinical Profile of Tubotympanic CSOM and Its Management With Special Reference to Site and Size of Tympanic Membrane Perforation, Eustachian Tube Function and Three Flap Tympanoplasty. Indian J Otolaryngol Head Neck Surg. 2012;64(1):5-12.

5. Morris P. Chronic suppurative otitis media. BMJ Clin Evid. 2012;2012:0507.

6. Verhoeff M, van der Veen EL, Rovers MM, Sanders EAM, Schilder AGM. Chronic suppurative otitis media: A review. International Journal of Pediatric Otorhinolaryngology. 2006;70(1):1-12.

7. Musiek FE, Shinn J, Chermak GD, Bamiou D-E. Perspectives on the pure-tone audiogram. Journal of the American Academy of Audiology. 2017;28(7):655-71.

8. Ars B, Dirckx J. Eustachian Tube Function. Otolaryngologic Clinics of North America. 2016;49(5):1121-33.
Medico-legal Update, April-June 2021, Vol. 21, No. 2 1023

9. Smith ME, Blythe AJC, Baker C, Zou CC, Hutchinson PJA, Tysome JR. Tests of Eustachian Tube Function: the Effect of Testing Technique on Tube Opening in Healthy Ears. Otology \& Neurotology. 2017;38(5):714-20.

10. Qureishi A, Lee Y, Belfield K, Birchall JP, Daniel M. Update on otitis media - prevention and treatment. Infect Drug Resist. 2014;7:15-24.

11. Sengupta A, Anwar T, Ghosh D, Basak B. A study of surgical management of chronic suppurative otitis media with cholesteatoma and its outcome. Indian J Otolaryngol Head Neck Surg. 2010;62(2):171-6.

12. Artono, Surarto B, Purnami N, Hutahaen F, Mahardhika MR. The Association of IL-1 Alpha Level and TNF Alpha Expressions on Bone Destruction in Chronic Suppurative Otitis Media and Cholesteatoma. Indian Journal of Otolaryngology and Head \& Neck Surgery. 2019.

13. Tadke KR, Lahane VJ, Wakode P. Role of Impedance Audiometry in Evaluation of Eustachian Tube Function and Its Correlation with Tympanoplasty Surgery Outcome: Our Experience. IOSR J Dental Med Sci. 2017;16(6):45-9.

14. Basavannaiah $\mathrm{S}$. The study of eustachian tube function in safe otitis media. International Journal of Current Research. 2016;8(7):34247 - 53.

15. Priya K, Karthikeyan P, Coumare V, Sambandan A. Evaluation of eustachian tube function in chronic suppurative otitis media (tubotympanic type) with reference to its treatment outcome. Indian Journal of Otology. 2012;18(4):179-83.

16. Joshi SS, Jagade M, Agarwal S, Ahire D. Tympanometry, a Prognostic Indicator of Myringoplasty with Assessment of Eustachian Tube Function. 2012. 